\title{
Guest Family Physician Commentaries
}

\author{
Tsveti Markova, MD
}

\section{Re: Characteristics of Medical Professional Liability Claims in Patients Treated by Family Medicine Physicians}

As family physicians, we are very committed to providing the highest quality of care to our patients. Our primary focus is to understand patients' unique needs and expectations and to address them accordingly. Unfortunately, living in a litigious society, we are not protected from liability claims. A liability claim does not equate with suboptimal care. Flannery et $\mathrm{al}^{1}$ offers insight about the most common liability risks experienced by family physicians. Being aware of these risks provides better understanding of risk management and liability prevention. Flannery et $\mathrm{al}^{1}$ report a comprehensive summary of data, collected by the Physician Insurers Association of America, which is not all inclusive of past claims but is probably representative of the nature of the claims affecting family physicians. It was interesting to note that family physicians were ranked third of the reported 28 specialties based on number of claims files against them, right after obstetrics/gynecology and internal medicine and above general surgery and orthopedics. The most prevalent "medical misadventure" was a diagnostic error, led by acute myocardial infarction and followed by breast cancer, appendicitis, and then lung and colon cancers. It is not surprising that coronary artery disease is the most commonly cited diagnostic error given the critical nature of the problem, atypical presentations, and being the

From the Department of Family Medicine and Public Health Sciences, Wayne State University, Detroit, MI.

Funding: none.

Conflict of interest: none declared.

Corresponding author: Tsveti Markova, MD, Wayne State University Family Medicine Residency Program, 1101 W. University Drive, 3 North, Rochester, MI 48307 (E-mail: tmarkova@med.wayne.edu).

\footnotetext{
See Related Articles on Pages 753,728 , and 762 .
}

leading cause of morbidity and mortality in our society. Cancer screening and early diagnosis is also a frequently encountered problem, so following strictly the US Preventive Services Task Force's guidelines is critical for better patient care as well as malpractice prevention. Against the popular belief that procedurally oriented providers are more prone to malpractice claims, the most prevalent procedure in this database was "diagnostic interview and evaluation." This data emphasizes once again the importance of establishing rapport with patients and their families and the value of open communication. Patients have a right to be equal partners in decision making and understanding their options for diagnosis and management. If the patient and the provider reach common ground, both compliance and outcomes improve. Highquality patient care and risk management principles are congruent and stem from effective doctorpatient communication.

\section{Re: Delivery of Confidential Care to Adolescent Males}

Adolescents represent a large group of patients who rarely visit primary care physicians' offices unless they have an acute problem or are being brought by concerned parents for a routine health maintenance visit. The causes of the highest morbidity and mortality in this age group are related to risk-taking behavior, such as violence, sexually transmitted infections, and substance abuse. Adolescents need professional advice and counseling on these topics but do not proactively seek it because they have privacy and trust issues. Rubin et al's ${ }^{2}$ qualitative study explores the attitudes of adolescent males and their mothers toward the provision of confidential care and addressing health concerns. Although there were some small differences between the 2 groups related to the prioritization of health concerns, they both agree on the importance of establishing rapport with a physician who knows the adolescent, is personable and caring, and provides an individualized message for prevention of high- 
risk behaviors. The boys shared their lack of trust that their sensitive information is kept private by the physicians and their staff. Advice for medical professionals would be to consistently reassure the young adults regarding their rights for confidentiality and the mechanisms in place to maintain this confidentiality. Boys believe that they know plenty about sexually transmitted infections and pregnancy protection from other sources, so exploring their knowledge during a "confidential visit" is critical to help them find best practices and avoid mistakes. Even though the mothers have mixed feelings about leaving the room, this protected "alone" time is important for the adolescent and physician to develop trust and mutual understanding. It is alarming that, even among this selected group of patients who are already under a family physicians' care and are concerned enough to decide to participate in the focus groups, the level of trust in physicians about highrisk behavior counseling is low. The study reveals an unmet need and urges physicians to respond to it. What better place for the adolescent to establish a solid relationship with the health care system but in their family physician's office? Knowing the adolescents as children and understanding the family dynamics and societal pressures help to create a long-lasting, strong rapport, which is essential for high-quality care.

\section{Re: An Empirical Investigation of Factors Influencing Career Satisfaction of Primary Care Physicians}

There have been nationwide studies in the past to determine physicians' satisfaction with their profession. More recently there has been an increasing need to assess career satisfaction factors that specifically influence primary care specialties. The health care climate is rapidly changing. The delivery system is reorganizing and placing more emphasis on transforming primary care practices into patient-centered medical homes to be able to provide comprehensive, coordinated, and team-based care that is enhanced by information technology.
The need for primary care physicians is escalating. The reality is that medical students' interest in primary care is low, the prestige of these specialties is low, the reimbursement system is not structured to compensate for preventive care and chronic disease management, and the administrative barriers are increasing. The dilemma is how to reverse these realities and eventually close the societal gap of primary care demand and supply. The survey by Deshpande and DeMello ${ }^{3}$ analyzes factors that influence career satisfaction of internal medicine physicians, pediatricians, and family medicine physicians. The main factors leading to lower job satisfaction were found to be ownership, threat of malpractice suits, and inadequate quality of care (eg, lack of available consultants, rejection of care decision by insurers, patients' inability to pay, and communication barriers). Interaction with patients and income were associated with increased career satisfaction. It is interesting to note that none of the demographic variables or practice characteristics (age, sex, use of information technology, location, etc) had a significant impact on career satisfaction. Understanding these factors presents a potential opportunity for health care reform to influence the current trends. Motivated, highly competent primary care physicians are the cornerstone for successful reform. It is important for policy makers and medical societies to advocate for changes to these conditions and provide an optimal environment for attracting, sustaining, and retaining highquality primary care physicians.

\section{References}

1. Flannery FT, Parikh PD, Oetgen WJ. Characteristics of medical professional liability claims in patients treated by family medicine physicians. J Am Board Fam Med 2010;23:753-61.

2. Rubin SE, McKee MD, Campos G, O'Sullivan LF. Delivery of confidential care to adolescent males. J Am Board Fam Med 2010;23:728-35.

3. Deshpande SP, DeMello J. An empirical investigation of factors influencing career satisfaction of primary care physicians. J Am Board Fam Med 2010; 23:762-9. 